\title{
FROM AMINO ACIDS TO ENZYMES: A PROPOSAL USING DIDACTIC GAMES TO REVIEW THE CONTENT OF PROTEINS
}

\begin{abstract}
Paulo Enrique Cuevas Mestanza', Sandro Henrique Dias Ribeiro ${ }^{1}$, Eloá Cunha de Moura ${ }^{1}$, Vitor de Freitas², Victória Riquena Grosche ${ }^{2}$, Foued Salmen Espindola ${ }^{3}$, Renata Santos Rodrigues ${ }^{3}$, Kelly Aparecida Geraldo Yoneyama Tudini³, Veridiana de Melo Rodrigues Ávila ${ }^{3}$
\end{abstract}

1 Universidade Federal de Uberlândia, Instituto de Biologia (Minas Gerais, Brasil), 2 Universidade Federal de Uberlândia, Instituto de Ciências Biomédicas (Minas Gerais, Brasil), 3 Universidade Federal de Uberlândia, Instituto de Genética e Bioquímica (Minas Gerais, Brasil)

Supported by: CNPq, FAPEMIG, UFU

INTRODUCTION: Biochemistry is a discipline offered in graduation courses. In general, the students define Biochemistry as "complex and extensive", since, in most cases, a broad content is ministered in a short period of time. The consequences of this context may be reflected in the lack of interest by the students. Thus, the use of alternative methodologies presents potential to improve this situation. OBJECTIVES: Develop and implement educational games about protein content to review and arouse students' interest in the discipline. MATERIALS AND METHODS: The educational games were made from available materials and low cost. The games were applied in extracurricular schedules in Biology, Biotechnology, Biomedicine and Agronomy courses of the Federal University of Uberlândia in the second half of 2015. All of this games count with the presence of a mediator to solve questions and correct mistakes that can appear. DISCUSSION AND RESULTS: Three educational games were created: "Amino Game 2.0", "Memo Protein" and "Race of Enzymes" which addressing the content of amino acid ionization, structure and function of proteins and enzymes, respectively. "AminoGame 2.0" is based on the correct assembly of structures of amino acids, dipeptides or tripeptides in according to conditions described on card game randomly selected by the player. "Memoprotein" is a memory game in which the player must correctly answer a question about protein to have the right to turn the cards of the game. Finally, "Race of Enzymes" is a board game in which the player must correctly answer questions about enzymes to have the right to advancing squares on the board. The application of three games showed good acceptance among students. CONCLUSION: "Amino Game 2.0", "Memo Protein" and "Race of Enzymes" were considered to be effective tools in the teaching of Biochemistry.

Keywords: Educational Games; Proteins; Teaching of Biochemistry 